Erroneous beliefs and emotional involvement as predictors of athletes' sports betting behavior and problems

Christopher M. Jones ${ }^{1}$ and Benjamin Noël ${ }^{2}$

${ }^{1}$ The University of Bremen, Institute for Public Health and Nursing Research, Bremen, Free Hanseatic City of Bremen, Germany

${ }^{2}$ German Sport University Cologne, Institute of Exercise Training and Sport Informatics, Cologne, Germany

Author Note

Correspondence concerning this article should be addressed to Christopher M. Jones, Institute of Public Health and Nursing Research, University of Bremen, Grazer Str. 4, 28359 Bremen, Germany.E-mail: jones@uni-bremen.de

All data and analysis scripts that support the findings of this study will be made available upon publication at https://osf.io/... 


\begin{abstract}
The sports betting market has been growing rapidly over the last years, as have reports of problematic gambling behavior associated with sports. Due to high prevalence rates and well documented struggles of international stars, athletes have been highlighted as a group at-risk. However, there currently remains a lack of research on specific risk-factors or mechanisms. To examine the influence of two potential risk-factors (erroneous beliefs and emotional involvement) on sports betting behaviour and problems, 201 athletes with different levels of expertise completed an online questionnaire. Using principal components as well as regression analyses, we find that emotional involvement strongly predicts betting problems whereas erroneous beliefs do not. However, distorted cognitions / beliefs were associated with higher volumes and more frequent betting activities. This might contribute to betting problems in the long run. These results highlight athletes' emotional involvement and erroneous beliefs as potential targets for future intervention and prevention efforts.
\end{abstract}

Keywords: sports betting; problem gambling; risk factors; erroneous beliefs; emotion 
Erroneous beliefs and emotional involvement as predictors of athletes' sports betting behavior and problems

Sports betting is an ever-growing business with rapidly increasing numbers of bettors and company turnover worldwide (Winters \& Derevensky, 2019). Recent technological advances have not only resulted in a strong shift towards online betting (i.e. sports betting is now the most prevalent form of online gambling) but also the introduction of innovations regarding the variety of bets one can chose from (e.g. in-play and micro-betting). This has led to a stepwise transformation from a periodically available to a continuously available form of gambling (Griffiths \& Auer, 2013). EU legislators have reacted to the resulting increased demand by publishing guidelines to inform public policy of its member states (European Commission, 2012). Accompanying this expansive trend, more and more treatment seeking gamblers report sports betting as their principal gambling activity, which has seen sports betting develop into a major public health concern (Parke \& Parke, 2019).

Across different populations, a plethora of general risk factors for sports betting related problems has been reported. Overall, young adult males appear to be the most at-risk group (Russell et al., 2019), with full-time employment or studying as well as being single and welleducated also associated with more sports betting related problems. Addressing psychosocial risk-factors, recent research has found feelings of added loyalty towards one's favorite team/player, competition among peers and the demonstration of knowledge as well as feelings of competence as potential drivers of betting behavior (Gordon et al., 2015). Perceived elements of skill could thus enhance social standing / acceptance and ego (Raymen \& Smith, 2020) but also increase excitement (Jenkinson et al., 2018). Additionally, sports bettors have been found to 
increase their excitement by placing a bet on a game they are watching, because they simply “enjoy a punt” (Jenkinson et al., 2018).

While several high-profile athletes - like former England international Andros Townsend - have reportedly suffered from problematic sports betting and seen their struggles documented in mass media, athletes in general (with different levels of expertise) have also been brought into focus as a potential high-risk group by different researchers (e.g. Derevensky et al., 2019; GrallBronnec et al., 2016; Weiss \& Loubier, 2010). They have been hypothesized to be at an elevated risk due to higher availability of betting venues, a general tendency for taking risks and competing with others (Curry \& Jiobu, 1995) as well as more generally high levels of social acceptability of sports betting in sports-related environments (for a review: Derevensky et al., 2019). Additionally, athletes have been reported to more likely bet on the sport they have played and prefer allegedly skill-based forms of gambling (Weiss \& Loubier, 2010).

Summarizing these findings, two important clusters of psychosocial risk factors for sports betting related problems have been suggested to be distinguishable from more general risk factors for gambling problems (Russel et al., 2019) and could contribute to the development and perpetuation of betting related problems. Firstly, multilayered emotional involvement has been reported to be an important driver of sports betting with fandom of players/teams, involvement with peers as well as the excitement when watching sports in general exerting an influence. Secondly, the perceived influence of domain specific knowledge has been reported to not only contribute to feelings of competency, but also drive actual betting behavior because of expected earnings and perceived higher chances of winning based on one's sports-specific knowledge. However, this perceived influence of knowledge has not only been shown to be false (Khazaal et 
al., 2012), but also represent the result of distorted cognitions and erroneous beliefs (Cantinotti et al., 2004).

Likewise, cognitive distortions and erroneous beliefs have been shown to be important predictors of behavior and problems alike across different forms of gambling. They play a key role in the development and perpetuation of gambling behavior and influence gambling severity. Medium and robust effect sizes have been reported for different cognitions and beliefs across different types of gambling (for a review: Goodie \& Fortune, 2013). Typical distorted cognitions / erroneous beliefs can include different forms of gambling related expectancies, beliefs about predictive control, distorted reframing / interpretation of gambling outcomes, experience and attribution of near-misses and an illusion of control. Although these cognitions and beliefs are not considered diagnostic criteria, they have still been targeted by different interventions and in clinical treatment (Goodie \& Fortune, 2013). However, no central process behind the different distortions and beliefs has been identified. Instead, a variety of distinguishable gambling type specific beliefs can be reported - some of them found more regularly and similar in their manifestations across several types of gambling (e.g. gambler's fallacy, cf. Kahneman \& Tversky, 1972).

Taking this into account, in a recent review Goodie and Fortune (2013) stated that no evidence for generally more important types of beliefs across different forms of gambling exists but that broader identification and assessment of specific beliefs related to each type of gambling can add value to clinical treatment and entry points for prevention (e.g. defining target groups at specific risk). Regarding sports betting specific beliefs and cognitions, recent research suggests that established scales like the GBQ (Steenbergh et al., 2002) might not be valid as the 
luck/perseverance and illusion of control-subscales were highly correlated $(r=.87)$ instead of representing distinguishable latent constructs (Russel et al., 2019).

In spite of this growing evidence base for the importance of erroneous beliefs / distorted cognitions and emotional involvement in the development and perpetuation of betting problems on the one hand and elevated rates of problem gambling driven by facilitating sports-related environments (e.g. availability, social norms etc.) in athletes on the other hand, these two streams of research have yet to be connected. This is especially surprising considering the emphasize sport betting related advertisements have put on emotional involvement as well as potential monetary gains based on domain-specific knowledge (Lopez-Gonzalez et al., 2018).

\section{Aims of the Present Research}

The present research thus aims to explore the role of sports betting-specific cognitive distortions / erroneous beliefs and emotional involvement with sports regarding betting behavior and problems alike. Both factors are assumed to play a central role in the evaluation of athletes as a group at risk for sports betting related problems.

Specifically, we hypothesize that higher rates of emotional involvement and cognitive distortions / erroneous beliefs are associated with increased betting behavior (number of bets, amount spent) as well as symptom experience during the past 12 months (status as problem gambler, number of symptoms, symptom occurrence) in athletes. 


\section{Methods}

\section{Overview}

To test whether erroneous beliefs / cognitive distortions and emotional involvement are associated with betting related symptoms as well as behavioral outcomes (e.g. betting frequency, wagered amount) in athletes, we conducted a cross-sectional online survey.

\section{Sampling}

A total sample of 641 athletes or former athletes was recruited from the general population of North Rhine-Westphalia with a strong advertisement focus on the German Sport University Cologne, Germany, in late 2017. From the total sample, 201 athletes met all inclusion criteria. Inclusion criteria were as follows: Participants had to be at least 18 years old, be able to respond to the online questionnaire in German, have bet money on sports events during the last 12 months and report intermediate or higher levels of expertise in a given sport.

Participants had a mean age of $29.52(\mathrm{SD}=11.05)$, were mostly male $(83.08 \%)$ and reported high socio-economic status $33.83 \%$ had completed at least a bachelor's degree, $34.83 \%$ earning more than 2000 Euro per month). $47.26 \%$ of participants (had) competed on a regional level (intermediate expertise), 32.84\% on a supra-regional level (higher expertise) and $11.94 \%$ even on a national level (highest expertise, cf. Swann et al., 2015). 53.73\% of participants mostly bet on games of their main type of sport. For additional sample characteristics see Supplement 1. 


\section{Measures}

\section{Item development}

To date, no scales exist to assess the specific role of erroneous beliefs, cognitive distortions and emotional involvement in predicting sports betting behavior. However, several scales have been developed and validated to accurately assess erroneous beliefs and cognitive distortions across many other different forms of gambling. Thus, we took several steps to develop new items for this study. First, we created a preliminary list of 33 items, loosely based on the widely used Gamblers Beliefs Questionnaire (GBQ; Steenbergh et al., 2002) and the Gambling Cognitions Inventory (GCI; McInnes et al., 2014). Here, we tried to not only incorporate both underlying factors of the GBQ (luck/perseverance, illusion of control) and the skill/attitude factor of the GCI, biased memory processes (Items 7 and 8), but to explicitly highlight the assumption of the importance of domain specific knowledge within these statements. We also included items addressing the framing of near-misses (Items 9 and 10) as well as the vast amount of options and ways to customize bets (Items 2, 6 and 18), as these might also contribute to the illusion of control - especially when connected to assumed domain knowledge. To additionally address the potential key role of emotional involvement in shaping sports betting behavior, we added domain specific statements (e.g. "Betting on my team even increases my hopes and fears!").

We then asked two expert practitioners working with treatment seeking sports bettors in Cologne, Germany to provide feedback and help reduce any redundancies. This process resulted in the 18-item list we provided participants with (all German and English item wordings can be found in the Supplementary Materials). All items were worded as statements and participants 
rated their agreement on a visual analog scale ranging from "not at all" (0) to "absolutely" (100; numeric values were not presented).

\section{Outcome Variables}

Bets per week and monthly expenses were assessed as behavioral outcomes. We asked participants how many bets they had placed per week on average during the last 12 months, with options on an 8-point scale ranging from "never" to "30 or more". Additionally, participants were asked to specify how much money they had spent on average per month during the last 12 months. Here, participants replied to an open question with only numerical values accepted. In addition to these self-reported behavioral outcomes, we assessed the number of DSM-V criteria (gambling disorder), occurrence of at least one DSM-V criterion as well as experiencing more than three DSM-V criteria (cut-off value for problematic / pathological gambling) during the last 12 months. To assess these nine criteria, we rephrased the original German DSM-V items and instead asked e.g. "Thinking about the last 12 months, have you felt the need to increase the amounts of money in order to achieve the desired excitement?" with participants stating "yes", "no" or "I don't know". This approach is in line with recent research and enables us to use the same cut-off values for problematic and pathological gambling used in other studies and the DSM-V (although the DSM-V additionally allows to specify current severity as "mild", "moderate", "severe"). Additionally, Goodie and Fortune (2013) in a recent review suggested to not only use screening instruments for gambling problems like the South Oaks Gambling Screen (SOGS, Lesieur \& Blume, 1987) but to rely on diagnostic criteria instead. 


\section{Analysis}

We used principal components analysis (PCA) to detect patterns of covariation between different items which might be due to underlying latent factors, e.g. erroneous thoughts / cognitive distortions and emotional involvement (Table 1).

We then used the composite score for each scale as predictors of problematic / pathological gambling, occurrence of at least one diagnostic criterion during the last 12 months (logistic regression respectively), number of criteria experienced during the last 12 months, average bets placed per week during last 12 months and average money spent per month (linear regression respectively). Each criterion was predicted in a separate model and we corrected for multiple testing (Bonferroni) with a resulting $\alpha$ of .01 . We used the same dataset for the PCA as well as the prediction of gambling problems and behavior.

\section{Results}

\section{Principal components analysis}

A principal components analysis (PCA) with oblique rotation ("oblimin") was conducted on the 18 pre-selected items (as described in the methods section). The Kaiser-Meyer-Olkin $(\mathrm{KMO})$ measure supported sampling adequacy $(\mathrm{KMO}=.90)$ with all $\mathrm{KMO}$ values for the individual items above .72. Between item correlations sufficiently large enough for PCA were indicated by the results of Barlett's test of sphericity, $\chi 2(153)=1770.49, p<.001$. To determine how many components to extract that account for more variance than is expected by chance (based on multiple sets of random data), we used parallel analysis. As Figure 1 depicts, the screeplot was rather ambiguous and the eigenvalue of the potential third component falls slightly below the average value for the corresponding components in the random data sets and should 
thus be excluded. Thus, we also explored a three-component solution (oblique rotation) but as the third component only consisted of two items and rendered interpreting the pattern matrix difficult, we settled for the suggested two-component solution. As no a priori theoretical reasoning suggested both factors to not be correlated, we then used oblique rotation that resulted in a more interpretable solution. Based on the resulting pattern matrix, we selected items that strongly resembled simple structure by meeting the following criteria: a) loading of above .45 on one component and b) lesser cross-loadings than .30 on the other component (see e.g. Brown, 2015). A second principal component analysis, conducted on this reduced set of items, revealed that the two-component solution accounted for $54.17 \%$ of the variance (component $1: 35.00 \%$, component 2: $19.17 \%)$.

Component 1 consisted of nine items aiming to capture erroneous beliefs and cognitive distortions and was thus labelled "cognitive component". Component 2 consisted of five items aiming to capture different aspects of emotional involvement and was thus labelled "involvement component". While component 1 indicated nearly excellent internal consistency $(\alpha=.89)$, component 2 yielded at least acceptable levels $(\alpha=.76)$. However, this might be due to the lower number of items forming component 2.

\section{Composite scores}

We created composite scores for both components by taking the mean of all item-values per participant. We did not include weighting for each item (DiStefano et al., 2009). Both composite score-distributions resemble a normal distribution, with "involvement"-scores slightly left- and "cognitive"-scores slightly right-skewed (Table 2; additional visualizations can be found in the supplements). 


\section{Predicting gambling problems}

Addressing research question 1, we had hypothesized that participants dichotomized status as non-problem or problem / pathological gamblers could be predicted from the strength of their erroneous beliefs / cognitive distortions and their emotional involvement. Table 3 and 4 show that only participants emotional involvement was a significant predictor of problem / pathological gambling $(\beta=0.05, \mathrm{p}<0.01, \mathrm{OR}=1.05)$ and number of criteria experienced $(\beta=$ 0.04, $\mathrm{p}<0.01)$. However, when looking at experience of any criterion during the past 12 months, we find that erroneous beliefs / cognitive distortions as well as emotional involvement both are significant predictors (Table 3). The stronger effect emotional involvement exerts on gambling problems becomes even more apparent when taking the concurrent effect sizes into account.

\section{Predicting gambling behavior}

Addressing research question 2, we had hypothesized that participants' betting behavior could be predicted from the strength of their erroneous beliefs / cognitive distortions and their emotional involvement. However, only participants' erroneous beliefs / cognitive distortions significantly predicted number of bets per week (with emotional evolvement not significant due to Bonferroni correcting) and average monthly expenses. While a one-point higher cognitionscale value was associated with on average .03 more bets per week, it was also associated with spending 6.68 Euros more per week on average. 


\section{Discussion}

The present research aimed to explore the role of sports betting-specific cognitive distortions / erroneous beliefs and emotional involvement regarding sports betting behavior (number of bets, amount spent) and problems (status as problem gambler, number of symptoms, symptom occurrence) alike.

In general, athlete participants reported high levels of emotional involvement when connecting betting and sports. On an item-level, the increased excitement is less connected to the act of betting itself (e.g. Items 13 and 17) than to the event connected with the bet (i.e. betting on live events, betting on one's favorite team / player). This is in line with previous research on nonathletes highlighting team / player-loyalty (Gordon et al., 2015) and watching games live (Jenkinson et al., 2018) as important factors driving betting-related excitement. In support of our first hypothesis, these higher rates of emotional involvement were associated with sports betting related problems. Specifically, stronger involvement predicted problem gambling, the experience of any DSM-V criteria during the last 12 months as well as the number of experienced criteria. These findings expand on previous research that had characterized emotional involvement as typical for sports bettors (Gordon et al., 2015; Jenkinson et al., 2018; Raymen \& Smith, 2020) but not yet relevant for psychopathology. Here, we not only show associations with status as problem gambler and symptom experience in general, but rather a linear association of criteria experienced and strength of emotional involvement. Comparing these findings with other recent research on sports betting-specific risk factors in non-athlete samples (e.g. Russell et al., 2019, finding no significant associations in multivariate models), this might indicate first evidence for athletes as a group at risk: While the expected excitement as well as sports involvement were 
associated with gambling problems in bivariate models, they were not when included in a multivariate (and additional penalized) model (Russel et al., 2019).

As gambling problems and gambling behaviors have been reported to be only moderately correlated ( $r$ between .34 and .61; Cowie et al., 2017), examining just one of both does not paint the full picture. Interestingly, in the present study athletes' involvement was not associated with betting behavior. This might be due to the strong similarities several of the items of the involvement component show with the DSM-V criteria. While these criteria only implicitly integrate concrete gambling behavior they put a more explicit focus on regulatory and affective aspects - both are strongly represented in our scale, too.

Athlete participants not only report high levels of emotional involvement, but also high levels of sports betting related erroneous beliefs and cognitive distortions. On an item-level, we found strong support for the various beliefs and distortions we presented. While we on average find less support for beliefs about betting and customization options contributing to perceived control over the outcome, we find stronger support for the general assumption of the importance of domain specific knowledge as well as the lesser randomness of sports betting outcomes and potentially distorted memory processes (Items 7 and 8). In support of our second hypothesis, these stronger erroneous beliefs / cognitive distortions were associated with more bets per week as well as higher monthly expenses. This is in line with research across different forms of gambling (Cowie et al., 2017) and expands these to the specific sports betting context. Cowie et al. (2017) however report an important distinction: While Luck/Chance-related distortions were associated with gambling behavior as well as problems, Skill/Attitude-related distortions were only associated with gambling behavior. The authors interpret these findings as in line with research suggesting games of skill to bring about persistent behavior (Dickerson, 1993), 
hypothesizing that higher perceived control over the game could result in higher perceived control of one's gambling and thus more gambling behavior. Following this line of thought, we hypothesize that this perceived control over one's gambling could also result in less reported problem gambling. Interestingly, in the present research erroneous beliefs / cognitive distortions neither predicted problem gambling nor the experience of any DSM-V criteria during the last 12 months or the number of experienced criteria. While this is in stark contrast to recent efforts by Russel et al. (2019) who reported not-sports specific beliefs / distortions (assessed with the GBQ) to be associated with sports betting problems - even in a penalized multivariate model including a diverse set of predictors - it might be interpreted as supporting the position highlighted before (Cowie et al., 2017).

To summarize these findings, we show that specifically assessing sports betting related cognitions and beliefs could add value to the understanding of related problems (and behavior, as key aspect of the continuous and manifold underlying process) in athletes. Here, the present research expands on previous efforts reporting sports betting specific risk factors in non-athlete samples (Russel et al., 2019), efforts on athlete-specific risk factors (e.g. Derevensky et al., 2019; Grall-Bronnec et al., 2016; Weiss \& Loubier, 2010) as well as work on different types of cognitive distortions and their influence on gambling problems and behavior (Cowie et al., 2017). By specifically targeting these cognitions and beliefs, this approach might add entry points for clinical treatment as well as prevention efforts and policy decisions.

\section{Limitations}

However, the present research has some limitations. Looking only at athletes without comparing them to non-athletes, our findings can only serve as a first hint towards declaring athletes as a group at risk because of their emotional involvement and higher rates of distorted 
cognitions / erroneous beliefs. Future research should address these questions, especially in the light of current advertising practices (Lopez-Gonzalez et al., 2018). From a methodological standpoint, several limitations should be highlighted. Survey-based research mostly relies on self-report, thus, behavioral outcomes are potentially biased. Additionally, we created new scales to assess emotional involvement and cognitive distortions / erroneous beliefs. Although they are associated with the focal outcomes and results are in line with existing research, both sub-scales are in need of additional validation and generalizable information on their psychometric properties. The preliminary nature of both scales is further based on the rather small sample size. Although more than ten participants per item included in the PCA completed the survey, a larger and more diverse sample could substantiate generalization of findings. Although young males with higher education have been repeatedly reported as risk group, also including lower SES groups should benefit the course.

\section{Implications}

In spite of these limitations, the present research also shows some potential. We find that both subscales help to expand on previous findings as they predict betting related problems as well as behavior in athletes. This is especially relevant in the light of recent findings suggesting that established general gambling related cognitive distortion scales like the GBQ might not be valid in the context of sports betting (Russel et al., 2019) and more general requests to identify specific beliefs / cognitions related to each type of gambling (Goodie \& Fortune, 2013).

Accordingly, we adopted a sports betting specific perspective, highlighting specific entry points for future treatment as well as prevention efforts and policy decisions. 


\section{Conflict of interest}

All authors declare no conflict of interest.

\section{Funding}

This research was supported by a grant from the Ministry for Health, Equalities, Care and Ageing of the State of North Rhine-Westphalia (now: Ministry for Regional Identity, Communities and Local Government, Building and Gender Equality) as a part of the “Aktionsplan gegen Sucht" (Action plan against addiction), project number 17. However, the funding source had no involvement in the study design, collection, analysis and interpretation of the data, writing of this paper as well as in the decision to submit this article for publication.

\section{Human and animal rights and informed consent}

All procedures performed in this study involving human participants were conducted in accordance with the ethical standards of the local institutional ethics committee and with the Helsinki Declaration of 1975, as revised in 2000. Informed consent was obtained from all patients for being included in the study. 


\section{References}

Brown, T. A. (2015). Confirmatory factor analysis for applied research, 2nd ed. The Guilford Press.

Cantinotti, M., Ladouceur, R., \& Jacques, C. (2004). Sports betting: Can gamblers beat randomness? Psychology of Addictive Behaviors, 18(2), 143-147. https://doi.org/10.1037/0893-164X.18.2.143

Cowie, M. E., Stewart, S. H., Salmon, J., Collins, P., Al-Hamdani, M., Boffo, M., Salemink, E., de Jong, D., Smits, R., \& Wiers, R. W. (2017). Distorted Beliefs about Luck and Skill and Their Relation to Gambling Problems and Gambling Behavior in Dutch Gamblers. Frontiers in Psychology, 8. https://doi.org/10.3389/fpsyg.2017.02245

Curry, T. J., \& Jiobu, R. M. (1995). Do Motives Matter? Modeling Gambling on Sports among Athletes. Sociology of Sport Journal, 12(1), 21-35. https://doi.org/10.1123/ssj.12.1.21

Derevensky, J. L., McDuff, D., Reardon, C. L., Hainline, B., Hitchcock, M. E., \& Richard, J. (2019). Problem gambling and associated mental health concerns in elite athletes: A narrative review. British Journal of Sports Medicine, 53(12), 761-766. https://doi.org/10.1136/bjsports-2019-100668

Dickerson, M. (1993). Internal and external determinants of persistent gambling: Problems in generalising from one form of gambling to another. Journal of Gambling Studies, 9(3), 225-245. https://doi.org/10.1007/BF01015920

DiStefano, C., Zhu, M., \& Mindrila, D. (2009). Understanding and Using Factor Scores: Considerations for the Applied Researcher. Practical Assessment, Research \& Evaluation, 14(20). https://doi.org/10.7275/da8t-4g52 
European Commission. (2012). Towards a comprehensive European framework for online gambling. Brussels: European Commission.

Gordon, R., Gurrieri, L., \& Chapman, M. (2015). Broadening an understanding of problem gambling: The lifestyle consumption community of sports betting. Journal of Business Research, 68(10), 2164-2172. https://doi.org/10.1016/j.jbusres.2015.03.016

Grall-Bronnec, M., Caillon, J., Humeau, E., Perrot, B., Remaud, M., Guilleux, A., Rocher, B., Sauvaget, A., \& Bouju, G. (2016). Gambling among European professional athletes. Prevalence and associated factors. Journal of Addictive Diseases, 35(4), 278-290. https://doi.org/10.1080/10550887.2016.1177807

Griffiths, M. D., \& Auer, M. (2013). The irrelevancy of game-type in the acquisition, development, and maintenance of problem gambling. Frontiers in Psychology, 3. https://doi.org/10.3389/fpsyg.2012.00621

Jenkinson, R., Lacy-Vawdon, C. de, \& Carroll, M. (2018). Weighing up the odds: Young men, sports and betting (Victoria) [Report]. Victorian Responsible Gambling Foundation. https://apo.org.au/node/184181

Kahneman, D., \& Tversky, A. (1972). Subjective probability: A judgment of representativeness. Cognitive Psychology, 3(3), 430-454. https://doi.org/10.1016/0010-0285(72)90016-3

Khazaal, Y., Chatton, A., Billieux, J., Bizzini, L., Monney, G., Fresard, E., Thorens, G., Bondolfi, G., El-Guebaly, N., Zullino, D., \& Khan, R. (2012). Effects of expertise on football betting. Substance Abuse Treatment, Prevention, and Policy, 7(1), 18. https://doi.org/10.1186/1747-597X-7-18 
Lesieur, H. R., \& Blume, S. B. (1987). The South Oaks Gambling Screen (SOGS): A new instrument for the identification of pathological gamblers. The American Journal of Psychiatry, 144(9), 1184-1188. https://doi.org/10.1176/ajp.144.9.1184

Lopez-Gonzalez, H., Guerrero-Solé, F., Estévez, A., \& Griffiths, M. (2018). Betting is Loving and Bettors are Predators: A Conceptual Metaphor Approach to Online Sports Betting Advertising. Journal of Gambling Studies, 34(3), 709-726. https://doi.org/10.1007/s10899-017-9727-x

McInnes, A., Hodgins, D. C., \& Holub, A. (2014). The Gambling Cognitions Inventory: Scale development and psychometric validation with problem and pathological gamblers. International Gambling Studies, 14(3), 410-431.

https://doi.org/10.1080/14459795.2014.923483

Parke, A., \& Parke, J. (2019). Transformation of Sports Betting into a Rapid and Continuous Gambling Activity: A Grounded Theoretical Investigation of Problem Sports Betting in Online Settings. International Journal of Mental Health and Addiction, 17(6), 13401359. https://doi.org/10.1007/s11469-018-0049-8

Raymen, T., \& Smith, O. (2020). Lifestyle gambling, indebtedness and anxiety: A deviant leisure perspective. Journal of Consumer Culture, 20(4), 381-399. https://doi.org/10.1177/1469540517736559

Russell, A. M. T., Hing, N., \& Browne, M. (2019). Risk Factors for Gambling Problems Specifically Associated with Sports Betting. Journal of Gambling Studies, 35(4), 12111228. https://doi.org/10.1007/s10899-019-09848-x 
Steenbergh, T. A., Meyers, A. W., May, R. K., \& Whelan, J. P. (2002). Development and validation of the Gamblers' Beliefs Questionnaire. Psychology of Addictive Behaviors, 16(2), 143-149. https://doi.org/10.1037/0893-164X.16.2.143

Swann, C., Moran, A., \& Piggott, D. (2015). Defining elite athletes: Issues in the study of expert performance in sport psychology. Psychology of Sport and Exercise, 16, 3-14. https://doi.org/10.1016/j.psychsport.2014.07.004

Weiss, S. M., \& Loubier, S. L. (2010). Gambling Habits of Athletes and Nonathletes Classified as Disordered Gamblers. The Journal of Psychology, 144(6), 507-521. https://doi.org/10.1080/00223980.2010.503248

Winters, K. C., \& Derevensky, J. L. (2019). A Review of Sports Wagering: Prevalence, Characteristics of Sports Bettors, and Association with Problem Gambling. Journal of Gambling Issues, 43(0), Article 0. https://doi.org/10.4309/jgi.2019.43.7 
Tables

Table 1

Summary of principal components analysis with oblimin rotation for 18 items $(\mathrm{N}=201)$.

\begin{tabular}{|c|c|c|c|c|c|}
\hline \multirow{3}{*}{ Item } & \multicolumn{2}{|c|}{$\underline{\text { Pattern Matrix }}$} & \multicolumn{3}{|c|}{$\underline{\text { Structure Matrix }}$} \\
\hline & Cognitive & Involvement & Cognitive & Involvement & Communalities \\
\hline & Component & Component & Component & Component & \\
\hline Item 1 & .47 & .43 & .64 & .62 & .57 \\
\hline Item 2 & .80 & & .79 & .29 & .63 \\
\hline Item 3 & .50 & .30 & .62 & .49 & .45 \\
\hline Item 4 & .67 & .22 & .76 & .48 & .61 \\
\hline Item 5 & .64 & .20 & .72 & .45 & .55 \\
\hline Item 6 & .71 & & .72 & .31 & .52 \\
\hline Item 7 & .63 & & .57 & & .34 \\
\hline Item 8 & .55 & & .57 & .28 & .33 \\
\hline Item 9 & .45 & .31 & .57 & .48 & .41 \\
\hline Item 10 & .42 & .31 & .54 & .48 & .38 \\
\hline Item 11 & .57 & & .64 & .41 & .44 \\
\hline Item 12 & .82 & & .84 & .37 & .71 \\
\hline Item 13 & & .58 & .41 & .65 & .46 \\
\hline Item 14 & .20 & .69 & .47 & .77 & .62 \\
\hline Item 15 & & .81 & .24 & .78 & .62 \\
\hline Item 16 & & .70 & & .63 & .42 \\
\hline Item 17 & .29 & .53 & .50 & .64 & .49 \\
\hline Item 18 & .88 & -.29 & .77 & & .66 \\
\hline Eigenvalue & 7.47 & 1.74 & & & \\
\hline$\%$ of variance & 32.78 & 18.42 & & & \\
\hline
\end{tabular}

Note: $\mathrm{N}=201$. Participants responded to the items on visual analog scales ranging from "not at all" (0) to "absolutely" (100; numeric values were not presented). Factor loadings < 2 are suppressed. Italic depicts items not retained in the reduced scales. 
Table 2

Descriptive statistics for the reduced two-factor solution ("cognitive component", "involvement component"; $\mathrm{N}=201$ ).

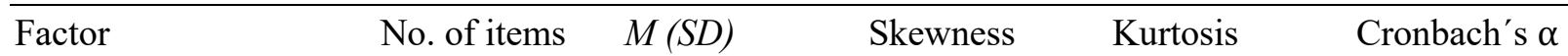

\begin{tabular}{lccccc}
\hline Cognitive Comp. & 9 & $39.87(23.57)$ & .19 & -.76 & .89 \\
Involvement Comp. & 5 & $48.31(21.84)$ & -.28 & -.48 & .76 \\
\hline
\end{tabular}

Note: $M$ and $S D$ represent mean and standard deviation, respectively.

Table 3

Summary of logistic regression models: Parameter estimates, standard errors, odds ratios with confidence intervals of each covariate.

\begin{tabular}{|c|c|c|}
\hline Predictor & Parameter Estimate (SE) & Odds Ratio $(95 \% \mathrm{CI})$ \\
\hline \multicolumn{3}{|l|}{ Model 1: } \\
\hline Intercept & $-5.11 * * *(0.83)$ & \\
\hline Cognitive Comp. & $0.02(0.01)$ & $1.02(0.99,1.04)$ \\
\hline Involvement Comp. & $0.05 * * *(0.01)$ & $1.05(1.02,1.08)$ \\
\hline \multicolumn{3}{|l|}{ Model 2: } \\
\hline Intercept & $-2.57 * * *(0.47)$ & \\
\hline Cognitive Comp. & $0.02 * *(0.01)$ & $1.02(1.01,1.04)$ \\
\hline Involvement Comp. & $0.03 * *(0.01)$ & $1.03(1.01,1.05)$ \\
\hline
\end{tabular}

Note: Model 1: Logistic regression model predicting problem gambling (DSM-V); Model 2: Logistic regression model predicting symptom (DSM-V) occurrence during past 12 months.

$* \mathrm{p}<0.05, * * \mathrm{p}<0.01, * * * \mathrm{p}<0.001$, bold: $\mathrm{p}<0.05$ 
Table 4

Summary of linear regression models: Parameter estimates, confidence intervals and fit statistics.

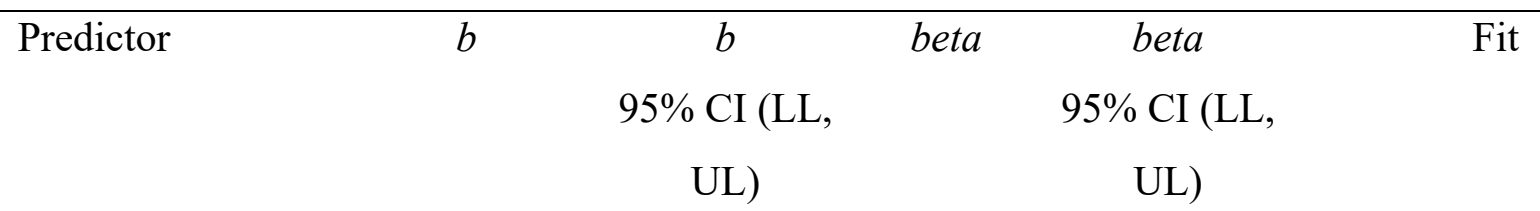

Model 1:

$\begin{array}{llccc}\text { Intercept } & \mathbf{- 1 . 0 5} * * & \mathbf{( - 1 . 7 7 , - 0 . 3 2 )} & & \\ \text { Cognitive Comp. } & 0.02 * & (0.00,0.03) & 0.16 & (0.02,0.31) \\ \text { Involvement Comp. } & \mathbf{0 . 0 4} * * * & \mathbf{( 0 . 0 2 , 0 . 0 5 )} & \mathbf{0 . 3 5} & \mathbf{( 0 . 2 0 , 0 . 5 0 )}\end{array}$

$R^{2}=.211^{* *}$

$95 \%$ CI $(.11, .30)$

Model 2:

$\begin{array}{lllll}\text { Intercept } & 0.65 & (-0.37,1.68) & & \\ \text { Cognitive Comp. } & \mathbf{0 . 0 3 * *} & (\mathbf{0 . 0 1 , 0 . 0 5 )} & \mathbf{0 . 2 3} & \mathbf{( 0 . 0 8 , 0 . 3 9 )} \\ \text { Involvement Comp. } & 0.03 * & (0.01,0.05) & 0.20 & (0.05,0.36)\end{array}$

$R^{2}=.145^{* *}$

$95 \%$ CI $(.06, .23)$

Model 3:

$\begin{array}{llccc}\text { Intercept } & -101.08 & (-270.48,68.32) & & \\ \text { Cognitive Comp. } & \mathbf{6 . 6 8}^{* *} & \mathbf{( 3 . 2 8 , ~ 1 0 . 0 9 )} & \mathbf{0 . 3 1} & \mathbf{( 0 . 1 5 , 0 . 4 7 )} \\ \text { Involvement Comp. } & 0.51 & (-3.17,4.18) & 0.02 & (-0.14,0.18)\end{array}$

$R^{2}=.104^{* *}$

$95 \%$ CI $(.03, .18)$

Note: Model 1: linear regression model predicting number of symptoms (DSM-V) during past 12 months; Model 2:

linear regression model predicting average number of bets per week; Model 3: linear regression model predicting average monthly expenses on sports betting during past 12 months. A significant $b$-weight indicates the beta-weight is also significant. $b$ represents unstandardized regression weights. beta indicates the standardized regression weights. $L L$ and $U L$ indicate the lower and upper limits of a confidence interval, respectively.

$* \mathrm{p}<0.05, * * \mathrm{p}<0.01, * * * \mathrm{p}<0.001$, bold: $\mathrm{p}<0.05$ 
Figures

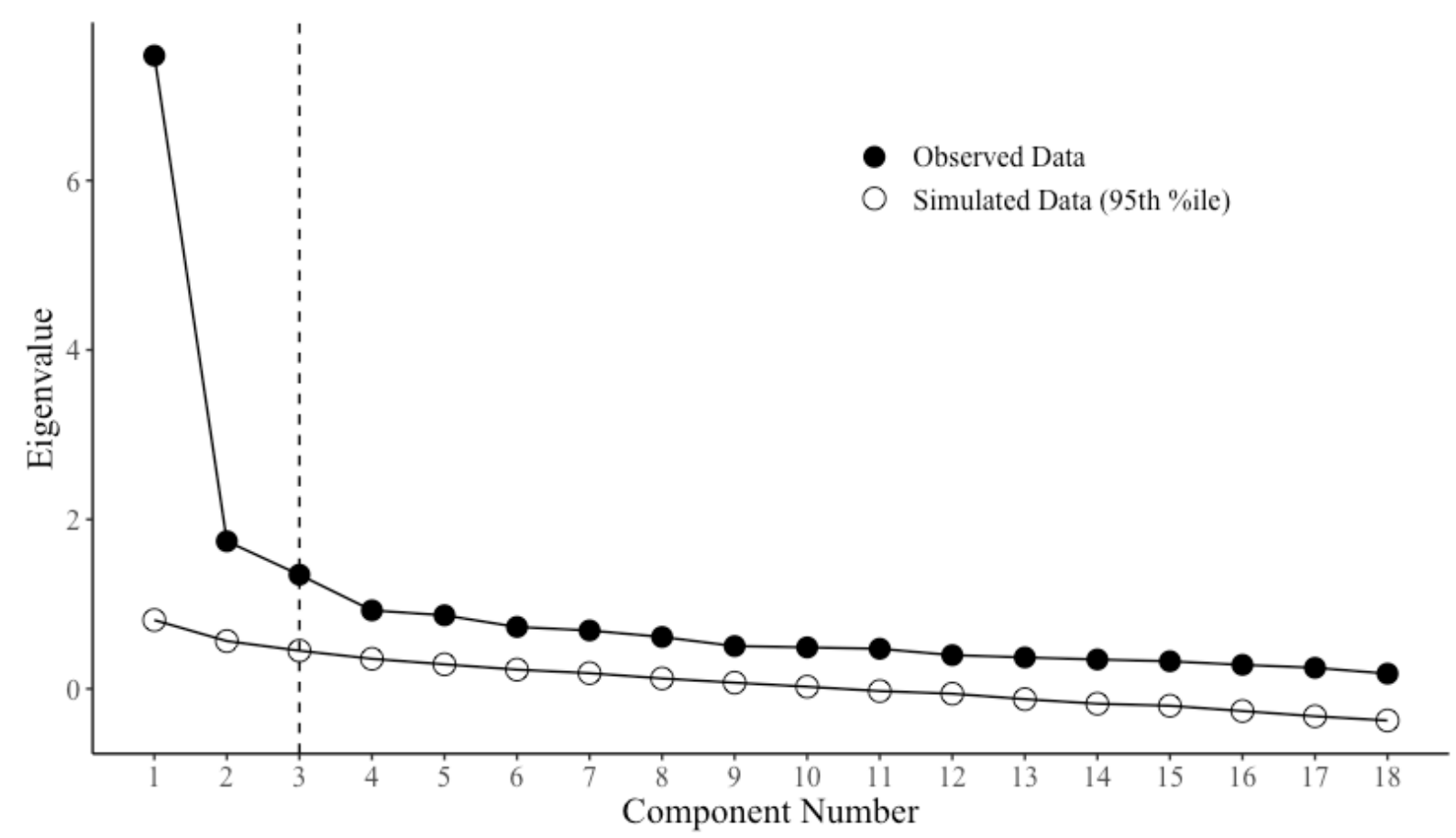

Figure 1. Scree plot with vertical line depicting suggested maximum number of components. To create this plot, we adapted R-code provided by Sakaluk \& Short (2016). 


\author{
Supplementary Materials
}

\title{
Material 1.
}

List of all items in English and German (original)

Item 1: „It gives me a good feeling when I have decided on a result based on my knowledge and my skills and put my money on it“"

„Es gibt mir ein gutes Gefühl, wenn ich aufgrund meines Wissens und meiner

Fähigkeiten ein Ergebnis ausgewählt und darauf gesetzt habe.“

Item 2: "I have looked very closely at the various betting options and offers"

„Ich habe mich sehr genau mit den verschiedenen Wettmöglichkeiten und -angeboten beschäftigt."

Item 3: "When I have decided on a result and put money on it, I feel competent"

„Wenn ich ein Ergebnis ausgewählt und Geld darauf gesetzt habe, fühle ich mich kompetent.“

Item 4: "Won bets are due to my knowledge and skills"

„Gewonnene Wetten sind zurückzuführen auf mein Wissen und meine Fähigkeiten.“

Item 5: "Won bets are due to my experience as a bettor"

„Gewonnene Wetten sind zurückzuführen auf meine Erfahrung als Wetter.“

Item 6: "The variety of betting options ensures that I have more control and can determine exactly how and where I can make a profit"

„Die Vielzahl von Wettmöglichkeiten sorgt dafür, dass ich mehr Kontrolle über das Wetten habe und genau bestimmen kann, wie und wo ich Gewinne erzielen kann.“

Item 7: "I can tell exactly who (and why) I bet on at my last big loss" „Ich kann genau sagen, auf wen (und warum) ich bei meinem letzten großen Verlust gesetzt habe."

Item 8: "I can tell exactly who (and why) I bet on at my last big win" „Ich kann genau sagen, auf wen (und warum) ich bei meinem letzten großen Gewinn gesetzt habe.“

Item 9: "Narrowly lost bets just show how good my assessment was" „Nur knapp verlorene Wetten zeigen immer wieder, wie gut meine Einschätzung war.”

Item 10: "From a narrowly lost bet, I learn for the next bet" „Aus einer knapp verlorenen Wette, lerne ich für das nächste Mal.“ 
Item 11: "Even supposedly unlikely sports results are less random / depend less on chance than in gambling."

„Auch vermeintlich unwahrscheinliche Sportergebnisse sind weniger zufallsbedingt / hängen weniger von Zufällen ab als bei Glücksspielen.“

Item 12: "I can attribute most successful bets to my skills and knowledge" „Ich kann die meisten erfolgreichen Wetten auf meine Fähigkeiten und mein Wissen zurückführen.“

Item 13: "After losses I already think about the next successful bet" „Nach Verlusten denke ich bereits an eine erfolgreiche weitere Wette.“

Item 14: "The prospect of big wins immediately improves my mood" „Die Aussicht auf große Gewinne verbessert augenblicklich meine Laune.“

Item 15: "Betting on games / competitions / races that I follow live, increases my hopes and fears even more."

„Wenn ich auf Spiele / Wettkämpfe / Rennen, die ich live verfolge, wette, steigert dies mein Hoffen und Bangen noch mehr.“

Item 16: "Betting on my club / my athlete, increases my hopes and fears even more" „Wenn ich auf meinen Verein / meinen Sportler wette, steigert dies mein Hoffen und Bangen noch mehr.“

Item 17: "The very moment I bet money on a result, I feel good." „Im Moment, in dem ich Geld auf ein Ergebnis setze, fühle ich mich gut.“

Item 18: „Bookmakers make mistakes when setting odds, which I can take advantage of “ „Buchmacher begehen Fehler bei der Quoten-Setzung, die ich ausnutzen kann.“ 


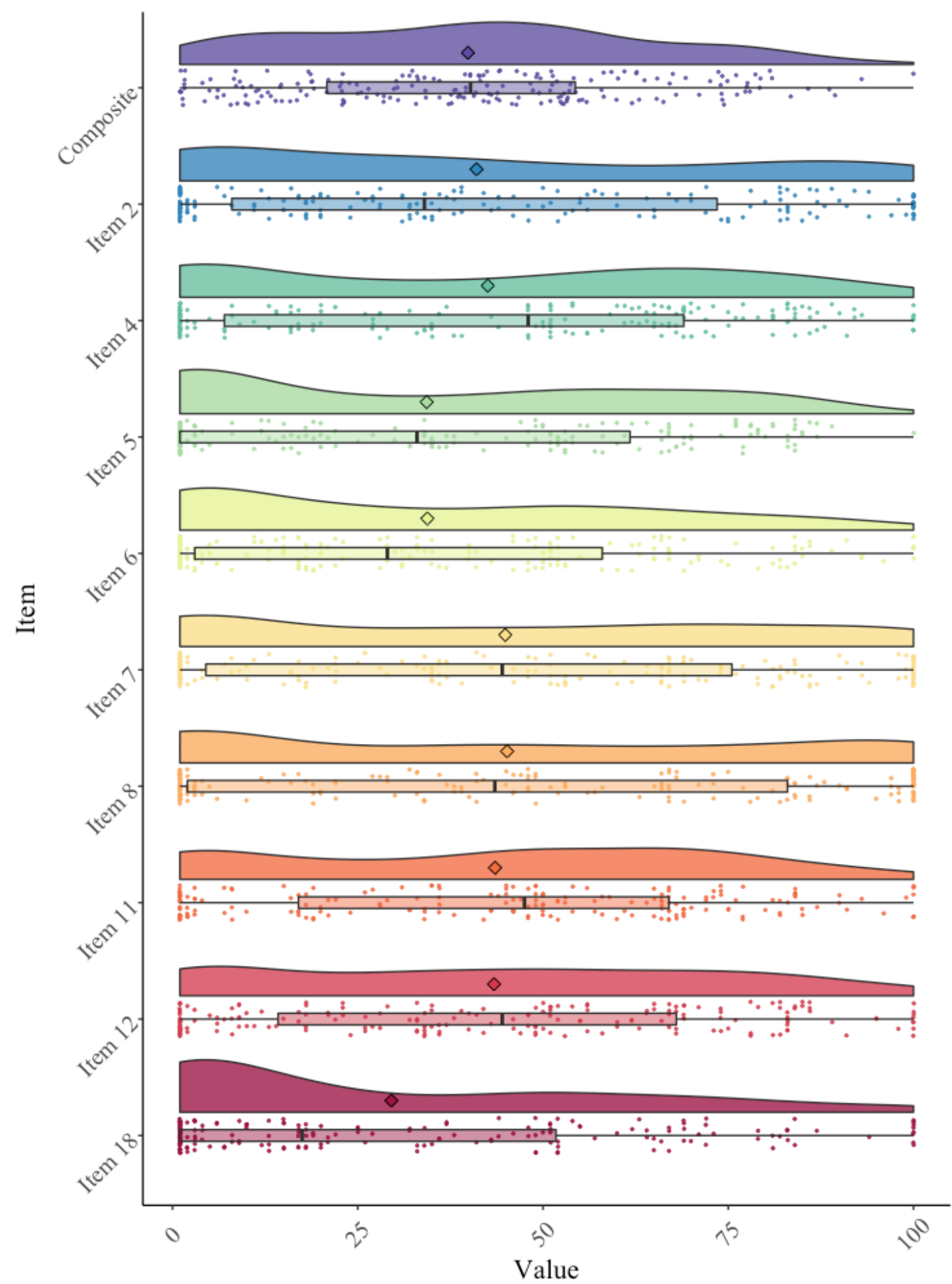

Material 2. Raincloud plots of items forming cognitive component and composite score. Dots depicting jittered values with embedded boxplots, density distributions above with means depicted as squares. 


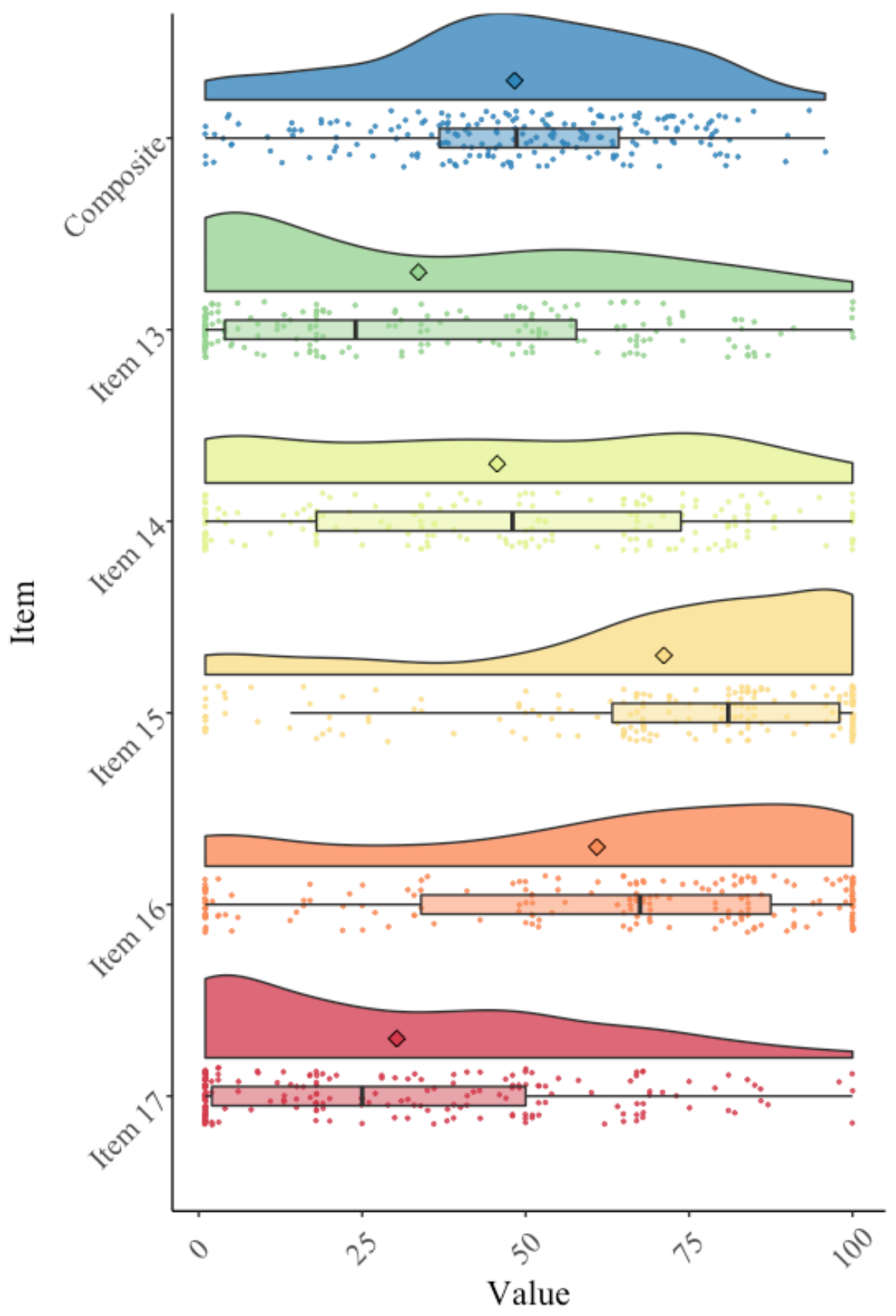

Material 3. Raincloud plots of items forming involvement component and composite score. Dots depicting jittered values with embedded boxplots, density distributions above with means depicted as squares. 
Material 4. Means, standard deviations, and correlations with confidence intervals of all items included in PCA.

\begin{tabular}{|c|c|c|c|c|c|c|c|c|c|c|c|c|c|c|c|c|c|c|c|}
\hline Variable & $M$ & $S D$ & 1 & 2 & 3 & 4 & 5 & 6 & 7 & 8 & 9 & 10 & 11 & 12 & 13 & 14 & 15 & 16 & 17 \\
\hline 1. Item 1 & 45.72 & 32.50 & & & & & & & & & & & & & & & & & \\
\hline 2. Item 2 & 41.49 & 34.45 & $\begin{array}{r}.51 * * \\
{[.39, .60]}\end{array}$ & & & & & & & & & & & & & & & & \\
\hline 3. Item 3 & 39.05 & 31.58 & $\begin{array}{r}.51^{* * *} \\
{[.40, .61]}\end{array}$ & $\begin{array}{r}.45^{* *} \\
{[.33, .55]}\end{array}$ & & & & & & & & & & & & & & & \\
\hline 4. Item 4 & 42.58 & 32.59 & $\begin{array}{r}.54^{* *} \\
{[.43, .63]}\end{array}$ & $\begin{array}{r}.52^{* *} \\
{[.42, .62]}\end{array}$ & $\begin{array}{r}.56 * * \\
{[.46, .65]}\end{array}$ & & & & & & & & & & & & & & \\
\hline 5. Item 5 & 34.39 & 30.69 & $\begin{array}{r}.47 * * \\
{[.36, .57]}\end{array}$ & $\begin{array}{r}.48^{* *} \\
{[.36, .58]}\end{array}$ & $\begin{array}{r}.44 * * \\
{[.32, .54]}\end{array}$ & $\begin{array}{r}.72 * * \\
{[.65, .78]}\end{array}$ & & & & & & & & & & & & & \\
\hline 6. Item 6 & 34.47 & 30.38 & $\begin{array}{r}.43 * * \\
{[.31, .54]}\end{array}$ & $\begin{array}{r}.53 * * \\
{[.43, .62]}\end{array}$ & $\begin{array}{r}.32 * * \\
{[.19, .44]}\end{array}$ & $\begin{array}{r}.46 * * \\
{[.34, .56]}\end{array}$ & $\begin{array}{r}.50 * * \\
{[.39, .60]}\end{array}$ & & & & & & & & & & & & \\
\hline 7. Item 7 & 44.96 & 35.58 & $\begin{array}{r}.24 * * \\
{[.10, .36]}\end{array}$ & $\begin{array}{r}.35^{* *} \\
{[.22, .46]}\end{array}$ & $\begin{array}{r}.24 * * \\
{[.10, .37]}\end{array}$ & $\begin{array}{r}.35^{* *} \\
{[.22, .47]}\end{array}$ & $\begin{array}{r}.33^{* *} \\
{[.20, .45]}\end{array}$ & $\begin{array}{r}.36 * * \\
{[.23, .48]}\end{array}$ & & & & & & & & & & & \\
\hline 8. Item 8 & 45.69 & 37.88 & $\begin{array}{r}.33^{* *} \\
{[.21, .45]}\end{array}$ & $\begin{array}{r}.41^{* *} \\
{[.29, .52]}\end{array}$ & $\begin{array}{r}.30^{* *} \\
{[.17, .42]}\end{array}$ & $\begin{array}{r}.32^{* *} \\
{[.19, .44]}\end{array}$ & $\begin{array}{r}.34 * * \\
{[.21, .46]}\end{array}$ & $\begin{array}{r}.38^{* *} \\
{[.26, .50]}\end{array}$ & $\begin{array}{r}.57^{* *} \\
{[.47, .66]}\end{array}$ & & & & & & & & & & \\
\hline 9. Item 9 & 32.27 & 29.19 & $\begin{array}{r}.44 * * \\
{[.32, .55]}\end{array}$ & $\begin{array}{r}.43^{* *} \\
{[.31, .53]}\end{array}$ & $\begin{array}{r}.43 * * \\
{[.31, .53]}\end{array}$ & $\begin{array}{r}.44 * * \\
{[.32, .55]}\end{array}$ & $\begin{array}{r}.42 * * \\
{[.30, .53]}\end{array}$ & $\begin{array}{r}.44 * * \\
{[.32, .55]}\end{array}$ & $\begin{array}{r}.16^{*} \\
{[.02, .29]}\end{array}$ & $\begin{array}{r}.21 * * \\
{[.07, .34]}\end{array}$ & & & & & & & & & \\
\hline 10. Item 10 & 31.34 & 28.86 & $\begin{array}{r}.41^{* *} \\
{[.29, .52]}\end{array}$ & $\begin{array}{r}.35 * * \\
{[.22, .46]}\end{array}$ & $\begin{array}{r}.32^{* *} \\
{[.19, .44]}\end{array}$ & $\begin{array}{r}.33^{* *} \\
{[.20, .45]}\end{array}$ & $\begin{array}{r}.47 * * \\
{[.36, .57]}\end{array}$ & $\begin{array}{r}.48^{* *} \\
{[.37, .58]}\end{array}$ & $\begin{array}{r}.22 * * \\
{[.08, .35]}\end{array}$ & $\begin{array}{r}.32^{* *} \\
{[.19, .44]}\end{array}$ & $\begin{array}{r}.52^{* *} \\
{[.42, .62]}\end{array}$ & & & & & & & & \\
\hline 11. Item 11 & 43.97 & 30.02 & {$\left[\begin{array}{r}.46^{* *} \\
{[.35, .57]}\end{array}\right.$} & $\begin{array}{r}.46^{* *} \\
{[.34, .56]}\end{array}$ & $\begin{array}{r}.40^{* *} \\
{[.28, .51]}\end{array}$ & $\begin{array}{r}.55^{* *} \\
{[.45, .64]}\end{array}$ & $\begin{array}{r}.42^{* *} \\
{[.30, .53]}\end{array}$ & $\begin{array}{r}.41^{* *} \\
{[.29, .52]}\end{array}$ & $\begin{array}{r}.34^{* *} \\
{[.21, .45]}\end{array}$ & $\begin{array}{r}.32^{* *} \\
{[.19, .44]}\end{array}$ & $\begin{array}{r}.34 * * \\
{[.21, .45]}\end{array}$ & $\begin{array}{r}.30^{* * *} \\
{[.17, .43]}\end{array}$ & & & & & & & \\
\hline 12. Item 12 & 43.66 & 30.82 & $\begin{array}{r}.55 * * \\
{[.45, .64]}\end{array}$ & $\begin{array}{r}.63 * * \\
{[.54, .71]}\end{array}$ & $\begin{array}{r}.53 * * \\
{[.42, .62]}\end{array}$ & $\begin{array}{r}.68 * * \\
{[.60, .75]}\end{array}$ & $\begin{array}{r}.58 * * \\
{[.49, .67]}\end{array}$ & $\begin{array}{r}.61 * * \\
{[.51, .69]}\end{array}$ & $\begin{array}{r}.43 * * \\
{[.31, .53]}\end{array}$ & $\begin{array}{r}.38^{* *} \\
{[.25, .49]}\end{array}$ & $\begin{array}{r}.47 * * \\
{[.36, .57]}\end{array}$ & $\begin{array}{r}.42 * * \\
{[.30, .53]}\end{array}$ & $\begin{array}{r}.51^{* *} \\
{[.40, .61]}\end{array}$ & & & & & & \\
\hline 13. Item 13 & 33.78 & 30.21 & $\begin{array}{r}.45^{* *} \\
{[.34, .56]}\end{array}$ & $\begin{array}{r}.40^{* *} \\
{[.27, .51]}\end{array}$ & $\begin{array}{r}.31^{* *} \\
{[.17, .43]}\end{array}$ & $\begin{array}{r}.40^{* *} \\
{[.28, .51]}\end{array}$ & $\begin{array}{r}.38^{* *} \\
{[.26, .50]}\end{array}$ & $\begin{array}{r}.33^{* *} \\
{[.20, .45]}\end{array}$ & $\begin{array}{r}.00 \\
{[-.14} \\
.14]\end{array}$ & $\begin{array}{r}.20^{* *} \\
{[.06, .33]}\end{array}$ & $\begin{array}{r}.36^{* *} \\
{[.24, .48]}\end{array}$ & $\begin{array}{r}.34^{* *} \\
{[.21, .46]}\end{array}$ & $\begin{array}{r}.28^{* *} \\
{[.15, .41]}\end{array}$ & $\begin{array}{r}.37 * * \\
{[.24, .48]}\end{array}$ & & & & & \\
\hline 14. Item 14 & 45.54 & 31.60 & $\begin{array}{r}.58^{* *} \\
{[.48, .66]}\end{array}$ & $\begin{array}{r}.35^{* *} \\
{[.22, .46]}\end{array}$ & $\begin{array}{r}.42^{* *} \\
{[.30, .53]}\end{array}$ & $\begin{array}{r}.44 * * \\
{[.32, .54]}\end{array}$ & $\begin{array}{r}.46 * * \\
{[.35, .56]}\end{array}$ & $\begin{array}{r}.32^{* *} \\
{[.19, .44]}\end{array}$ & $\begin{array}{r}.22 * * \\
{[.08, .35]}\end{array}$ & $\begin{array}{r}.34 * * \\
{[.22, .46]}\end{array}$ & $\begin{array}{r}.40^{* *} \\
{[.28, .51]}\end{array}$ & $\begin{array}{r}.38^{* *} \\
{[.25, .49]}\end{array}$ & $\begin{array}{r}.44^{* *} \\
{[.32, .54]}\end{array}$ & $\begin{array}{r}.40^{* *} \\
{[.28, .51]}\end{array}$ & $\begin{array}{r}.48 * * \\
{[.36, .58]}\end{array}$ & & & & \\
\hline 15. Item 15 & 70.99 & 30.08 & $\begin{array}{r}.36^{* *} \\
{[.23, .47]}\end{array}$ & $\begin{array}{r}.23^{* *} \\
{[.10, .36]}\end{array}$ & $\begin{array}{r}.31^{* *} \\
{[.18, .43]}\end{array}$ & $\begin{array}{r}.36^{* *} \\
{[.23, .47]}\end{array}$ & $\begin{array}{r}.24 * * \\
{[.11, .37]}\end{array}$ & $\begin{array}{r}.22^{* *} \\
{[.08, .34]}\end{array}$ & $\begin{array}{r}.17 * \\
{[.04, .31]}\end{array}$ & $\begin{array}{r}.21^{* *} \\
{[.08, .34]}\end{array}$ & $\begin{array}{r}.30^{* *} \\
{[.16, .42]}\end{array}$ & $\begin{array}{r}.28^{* *} \\
{[.15, .41]}\end{array}$ & $\begin{array}{r}.30^{* *} \\
{[.17, .42]}\end{array}$ & $\begin{array}{r}.27 * * \\
{[.14, .40]}\end{array}$ & $\begin{array}{r}.38^{* *} \\
{[.25, .49]}\end{array}$ & $\begin{array}{c}.44 * * \\
{[.32, .54]}\end{array}$ & & & \\
\hline 16. Item 16 & 60.76 & 33.72 & $\begin{array}{r}.21^{* *} \\
{[.07,34]}\end{array}$ & $\begin{array}{r}.06 \\
{[-.08,} \\
.20]\end{array}$ & $\begin{array}{r}.19 * * \\
{[.06, .32]}\end{array}$ & $\begin{array}{r}.22^{* *} \\
{[.08, .35]}\end{array}$ & $\begin{array}{c}.17^{*} \\
{[.04, .30]}\end{array}$ & $\begin{array}{r}.14^{*} \\
{[.00, .27]}\end{array}$ & $\begin{array}{r}.19^{* *} \\
{[.06, .32]}\end{array}$ & $\begin{array}{r}.26^{* *} \\
{[.13, .39]}\end{array}$ & $\begin{array}{r}.09 \\
{[-.05} \\
.23]\end{array}$ & $\begin{array}{r}.23^{* *} \\
{[.10, .36]}\end{array}$ & $\begin{array}{r}.18^{*} \\
{[.04, .31]}\end{array}$ & $\begin{array}{r}.15^{*} \\
{[.01, .29]}\end{array}$ & $\begin{array}{r}.21^{* *} \\
{[.08, .34]}\end{array}$ & $\begin{array}{c}.31^{* *} \\
{[.17, .43]}\end{array}$ & $\begin{array}{r}.58^{* *} \\
{[.48, .67]}\end{array}$ & & \\
\hline 17. Item 17 & 29.88 & 27.40 & $\begin{array}{r}.50^{* *} \\
{[.39, .60]}\end{array}$ & $\begin{array}{r}.40^{* *} \\
{[.28, .51]}\end{array}$ & $\begin{array}{r}.49 * * \\
{[.37, .59]}\end{array}$ & $\begin{array}{r}.34 * * \\
{[.21, .46]}\end{array}$ & $\begin{array}{r}.39 * * \\
{[.27, .51]}\end{array}$ & $\begin{array}{r}.36 * * \\
{[.23, .47]}\end{array}$ & $\begin{array}{r}.17^{*} \\
{[.03, .30]}\end{array}$ & $\begin{array}{r}.31 * * \\
{[.18, .43]}\end{array}$ & $\begin{array}{r}.42^{* *} \\
{[.30, .53]}\end{array}$ & $\begin{array}{r}.34 * * \\
{[.22, .46]}\end{array}$ & $\begin{array}{r}.37 * * \\
{[.24, .48]}\end{array}$ & $\begin{array}{r}.38^{* *} \\
{[.26, .49]}\end{array}$ & $\begin{array}{r}.49 * * \\
{[.37, .59]}\end{array}$ & $\begin{array}{c}.59 * * \\
{[.49, .67]}\end{array}$ & $\begin{array}{r}.36^{* *} \\
{[.24, .48]}\end{array}$ & $\begin{array}{c}.16^{*} \\
{[.02, .29]}\end{array}$ & \\
\hline 18. Item 18 & 29.69 & 30.77 & $\begin{array}{r}.36 * * \\
{[.23, .47]}\end{array}$ & $\begin{array}{r}.65^{* *} \\
{[.57, .73]}\end{array}$ & $\begin{array}{r}.41^{* *} \\
{[.29, .52]}\end{array}$ & $\begin{array}{r}.47^{* *} \\
{[.36, .58]}\end{array}$ & $\begin{array}{r}.42^{* *} \\
{[.29, .52]}\end{array}$ & $\begin{array}{r}.47^{* *} \\
{[.35, .57]}\end{array}$ & $\begin{array}{r}.37 * * \\
{[.25, .48]}\end{array}$ & $\begin{array}{r}.37 * * \\
{[.25, .49]}\end{array}$ & $\begin{array}{r}.34 * * \\
{[.21, .45]}\end{array}$ & $\begin{array}{r}.33^{* *} \\
{[.20, .45]}\end{array}$ & $\begin{array}{r}.43^{* *} \\
{[.31, .54]}\end{array}$ & $\begin{array}{r}.60^{* *} \\
{[.50, .68]}\end{array}$ & $\begin{array}{r}.24 * * \\
{[.10, .37]}\end{array}$ & $\begin{array}{c}.14 \\
{[-.00, .27]}\end{array}$ & $\begin{array}{r}.05 \\
{[-.09} \\
.19]\end{array}$ & $\begin{array}{c}.00 \\
{[-.14, .14]}\end{array}$ & $\begin{array}{r}.31^{* *} \\
{[.18, .43]}\end{array}$ \\
\hline
\end{tabular}

Note. $M$ and $S D$ are used to represent mean and standard deviation, respectively. Values in square brackets indicate the $95 \%$ confidence interval for each correlation. * indicates $p<.05$. ** indicates $p<.01$. 